\title{
OPEN Author Correction: A new species of early-diverging Sauropodiformes from the Lower Jurassic Fengjiahe Formation of Yunnan Province, China
}

\author{
Claire Peyre de Fabrègues, Shundong Bi, Hongqing Li, Gang Li, LeiYang \& Xing Xu \\ Correction to: Scientific Reports https://doi.org/10.1038/s41598-020-67754-4, published online 03 July 2020
}

Peyre de Fabrègues et al. (2020), which was published electronically, does not include evidence of registration in ZooBank within the work itself, which is a requirement by Article 8.5.3 of the International Code of Zoological Nomenclature ${ }^{1}$. Therefore, the newly proposed species-group name Irisosaurus yimenensis is not available.

This publication has been registered in ZooBank with the LSID: urn:lsid:zoobank.org:act:462C8657-095A-41F2AF81-E0F28185ABAC. The following 'Zoobank' and 'Nomenclatural Acts' subsections appear below, along with the 'Systematic Paleontology' section of the original Article ${ }^{2}$. In addition, the 'Etymology' subsection has been corrected below to reflect the origin of the species-group name.

Systematic Paleontology.

Dinosauria Owen, 1842

Saurischia Seeley, 1887

Sauropodomorpha von Huene, 1932

Massopoda Yates, 2007

Sauropodiformes Sereno, 2007

Irisosaurus yimenensis gen. et sp. nov.

Zoobank.

urn:lsid:zoobank.org:act:462C8657-095A-41F2-AF81-E0F28185ABAC.

Etymology.

The generic nomen, from the latin iris (rainbow, reflections and by extension, iridescent), refers to the famous iridescent clouds of Yunnan Province (彩云之南). The specific epithet refers to Yimen County, where the type locality is located.

Nomenclatural Acts.

The electronic version of this article in Portable Document Format (PDF) will represent a published work according to the International Commission on Zoological Nomenclature (ICZN), and hence the new names contained in the electronic version are effectively published under that Code from the electronic edition alone. This published work and the nomenclatural acts it contains have been registered in ZooBank, the online registration system for the ICZN. The ZooBank LSIDs (Life Science Identifiers) can be resolved and the associated 
information viewed through any standard web browser by appending the LSID to the prefix https://zoobank.org/. The LSID for this publication is: [urn:lsid:zoobank.org:pub:5E157E76-19E1-48D9-AD7A-A1302CF81D96]. The online version of this work is archived and available from the following digital repositories: PubMed Central and CLOCKSS.

\section{References}

1. Amendment of Articles 8, 9, 10, 21 and 78 of the International Code of Zoological Nomenclature to expand and refine methods of publication. ZooKeys 219, 1-10, https://doi.org/10.3897/zookeys.219.3944 (2012).

2. Peyre de Fabrègues, C. et al. A new species of early-diverging Sauropodiformes from the Lower Jurassic Fengjiahe Formation of Yunnan Province, China. Sci. Rep. 10, 10961. https://doi.org/10.1038/s41598-020-67754-4 (2020).

(1) Open Access This article is licensed under a Creative Commons Attribution 4.0 International cc) License, which permits use, sharing, adaptation, distribution and reproduction in any medium or format, as long as you give appropriate credit to the original author(s) and the source, provide a link to the Creative Commons licence, and indicate if changes were made. The images or other third party material in this article are included in the article's Creative Commons licence, unless indicated otherwise in a credit line to the material. If material is not included in the article's Creative Commons licence and your intended use is not permitted by statutory regulation or exceeds the permitted use, you will need to obtain permission directly from the copyright holder. To view a copy of this licence, visit http://creativecommons.org/licenses/by/4.0/.

(C) The Author(s) 2020 